Çukurova Üniversitesi Mühendislik Fakültesi Dergisi, 36(1), ss. 141-154, Mart 2021

Cukurova University Journal of the Faculty of Engineering, 36(1), pp. 141-154, March 2021

\title{
Erkenez Havzası CBS Matris Yöntemi ile Heyelan Duyarlılık Değerlendirmesi
}

\author{
Eser KOÇ ${ }^{1}$, Muhterem KÜÇÜKÖNDER ${ }^{* 2}$ \\ ${ }^{1}$ Kahramanmaraş Sütçü İmam Üniversitesi, Sosyal Bilimler Enstitüsü, Coğrafya Bölümü, \\ Kahramanmaraş \\ ${ }^{2}$ Kahramanmaraş Sütçü Imam Üniversitesi, Fen-Edebiyat Fakültesi, Coğrafya Bölümü, \\ Kahramanmaraş
}

Geliş tarihi: 11.02.2021 Kabul tarihi: 31.03 .2021

$\ddot{\mathbf{O z}}$

Ülkemizde depremden sonra en fazla yaşanan doğal afetler arasında heyelanlar yer almaktadır. Heyelan duyarlılık çalışmaları ise bu afetlerin yarattı̆̆ mekânsal heyelan meydana gelme olasılıklarını haritalamayı amaçlamaktadır. Ülkemizde yağış ve litolojik faktörler dikkate alındığında heyelan olayları birçok bölgemizde yaşanmaktadır. Erkenez havzası topoğrafik, jeolojik ve meteorolojik faktörler dikkate alındığında Kahramanmaraş ilinde heyelan olaylarının yoğunlaştığı bölgelerden biridir. Havzanın heyelan duyarlılık analizi heyelan envanterine dayalı çok değişkenli haritalama birimlerinde olası kombinasyonlar arasında heyelanlı ve heyelansız alan ayrımına dayanan CBS Matris modeli ile gerçekleştirilmiştir. Bu modelde, sayısal yükseklik modeli (SYM), litolojik birimler, arazi kullanımı, eğim, bakı, normalize fark bitki indeksi (NDVI) ve topoğrafik nemlilik indeksi (TWI) parametreleri kullanılmıştır. $265 \mathrm{~km}^{2}$ alana sahip havzanın \%4,5'i heyelanlı bölgedir. Havzada \%6,97'si düşük, \%3,11'i orta, \%1,37'si yüksek, \%1,2'si çok yüksek derecede heyelana duyarlı alanlar olarak tespit edilmiştir. Havza için üretilen heyelan duyarlılık haritaları ile ileriye dönük yerleşim planlamalarında sorunların azaltılması ve çözümü yönünde pozitif etkisi olacağı düşünülmektedir.

Anahtar Kelimeler: Erkenez havzası, Heyelan, CBS matris, Heyelan duyarlılık

\section{Landslide Susceptibility Assessment with GIS Matrix Method in Erkenez Watershed}

\begin{abstract}
Landslides are among the most common natural disasters after earthquakes in our country. Landslide susceptibility studies aim to map the probability of spatial landslides by estimating the extent of the impact of these disasters before they occur. The Erkenez watershed is one of the regions where the landslide events are concentrated in Kahramanmaras, considering the topographic, geological and meteorological factors. The landslide susceptibility analysis of the watershed was carried out with the GISMatrix model based on the separation of landslide and non-landslide areas between possible combinations in multivariate mapping units based on landslide inventory. In this model, digital elevation model (DEM), lithological units, land use, slope, aspect, normalized difference plant index (NDVI) and
\end{abstract}

*Sorumlu yazar (Corresponding author): Muhterem KÜÇÜKÖNDER, muhteremkucukonder@ksu.edu.tr 
topographic wetness index (TWI) parameters were used. The study area is $265 \mathrm{~km}^{2}$ and $4.5 \%$ of it is landslide zone. In the watershed, $6.97 \%$ are low, $3.11 \%$ are medium, $1.37 \%$ are high, and $1.2 \%$ are very high landslide sensitive areas. It is thought that the landslide susceptibility maps produced for the watershed will have a positive effect in reducing and solving problems in settlement planning.

Keywords: Erkenez watershed, landslide, GIS matrix, landslide susceptibility

\section{GÍRIŞ}

Doğal süreçler ya da insan etkileri ile meydana gelen heyelan; kayaç, toprak, yamaç molozu, yapay dolgu veya bunların bir kombinasyonunda dâhil olmak üzere eğim yönünde malzemelerin aşağı doğru hareketine neden olan çeşitli süreçleri tanımlamaktadır [1]. Afet boyutuna ulaşmasını engellemek açısından potansiyel heyelan alanların tespit edilmesi meydana gelebilecek maddi ve can kayıplarının önlenmesi açısından büyük önem taşımaktadır. Heyelan duyarlılık analizlerinde, topoğrafik etkiler ile doğal ve insan kaynaklı birden fazla faktör bir arada değerlendirilmelidir [2-5]. Bu sebeple duyarlılık analizleri uygulanırken Coğrafi Bilgi Sistemleri (CBS) temelli veri işleme süreçleri ile istatistiksel ve nicel analiz yöntemleri kullanılmaktadır. Duyarlılık analizlerinde CBS tabanlı oluşturulan modellere ait tüm değişkenler ve parametreler girilerek hızlı, güvenilir ve doğru sonuçlar elde edilebilmektedir [6].

Heyelan duyarlılık kavramı, herhangi bir zamansal çıkarım olmaksızın heyelana eğilimli alanları belirlemek amaciyla heyelana hazırlayıcı faktörlerin mekânsal dağılımının değerlendirilmesidir [7-10]. Bu yaklaşım, heyelan envanterlerinin, yağışların meteorolojik kayıtlarının eksik veya daha az olduğu ve heyelanları tetikleyen depremlerin büyüklüğü/yoğunluğu hakkında verilen olmadığ1 veya temin edilmesinin zor olduğu alanlar için kullanışlı bulunmaktadır [6,10]. Heyelan duyarlılığın mekânsal olarak hesaplanması, toplam heyelan yoğunluğu ya da muhtemel sıklığı, rölatif tehlikenin bir ifadesi olarak kabul edilmektedir $[5,11,12]$.

Günümüzde, heyelan duyarlılığını CBS ortamında analiz etmek için pek çok yöntem bulunmaktadır $[2,13,14]$. Bu teknikler, hazırlayıcı faktörler ve gerçekleşen heyelanların bölgesel dağılımı arasındaki karşılaştırmaya dayanmaktadır [15-20]. Tüm ele alınan parametreler heyelanların mekânsal gerçekleme olasılığını temsil etmektedir [5,9].

Heyelan duyarlılığı çalışmalarında farklı yaklaşımlar kullanılmakta olup literatürde genel olarak; Frekans oranı, Analitik Hiyerarşi Yöntemi, Çok değişkenli istatistik yöntemi olan Lojistik regresyon ve Yapay sinir ağları yöntemleri yer almaktadir [4,21-25].

Çalışma alanı olan Erkenez Havzası, geçmiş yıllarda heyelan yaşanan ve heyelan aktivitesi devam eden bir bölgedir. Gelişen yerleşme sahaları ile kentleşme artmakta ve hızlı değişen arazi kullanım koşulları planlama sürecinde olası heyelanların dikkate alınması zorunluluğunu ortaya çıkarmaktadır. $\mathrm{Bu}$ çalışmada Erkenez Havzasında CBS Matris tekniği kullanılarak heyelan duyarlılık değerlendirilmesi gerçekleştirilmiştir.

\section{1. Çalışma Alanı}

Çalışma alanı Erkenez Havzası, Kahramanmaraş'ın doğusunda yer alan Dulkadiroğlu ilçesi sınırları içerisinde 265 km²'lik alanda yer almaktadır (Şekil 1). Çalışma alanı yükselti değerleri, Maraş ovası vadi tabanında 450'den başlayarak Ahir Dağına doğru 2350 m arasında değişmektedir. Genel olarak engebeli bir araziye sahip havza içerisinde 14 tane küçük yerleşim birimi bulunmaktadır. Havzada 1100 ile $1400 \mathrm{~m}$ rakım arasında bulunan Kozludere Mahallesi havzanın en yüksek yerleşim alanıdır. Dereköy ve Yusufhacılı mahalleleri ise $800 \mathrm{~m}$ yükseltisiyle havza içindeki en alçak yerleşim yerleridir. Akdeniz İklimi özellikleri gözlenen bölgede yıllık ortalama yağış miktarı 719,7 mm' dir [47]. En çok yağış aralık ve ocak aylarında ortalama $121 \mathrm{~mm}$ düşmektedir. Havza da ortalama 
sıcaklıklar değişiklik göstermektedir. Yüksek kesimlerde ortalama sicaklık değerleri $10,5{ }^{\circ} \mathrm{C}$ olarak ölçülmektedir. Şehir merkezine yakın yerleșmelerde sicaklık değerleri ortalama $14,7^{\circ} \mathrm{C}$ 'dir [47].

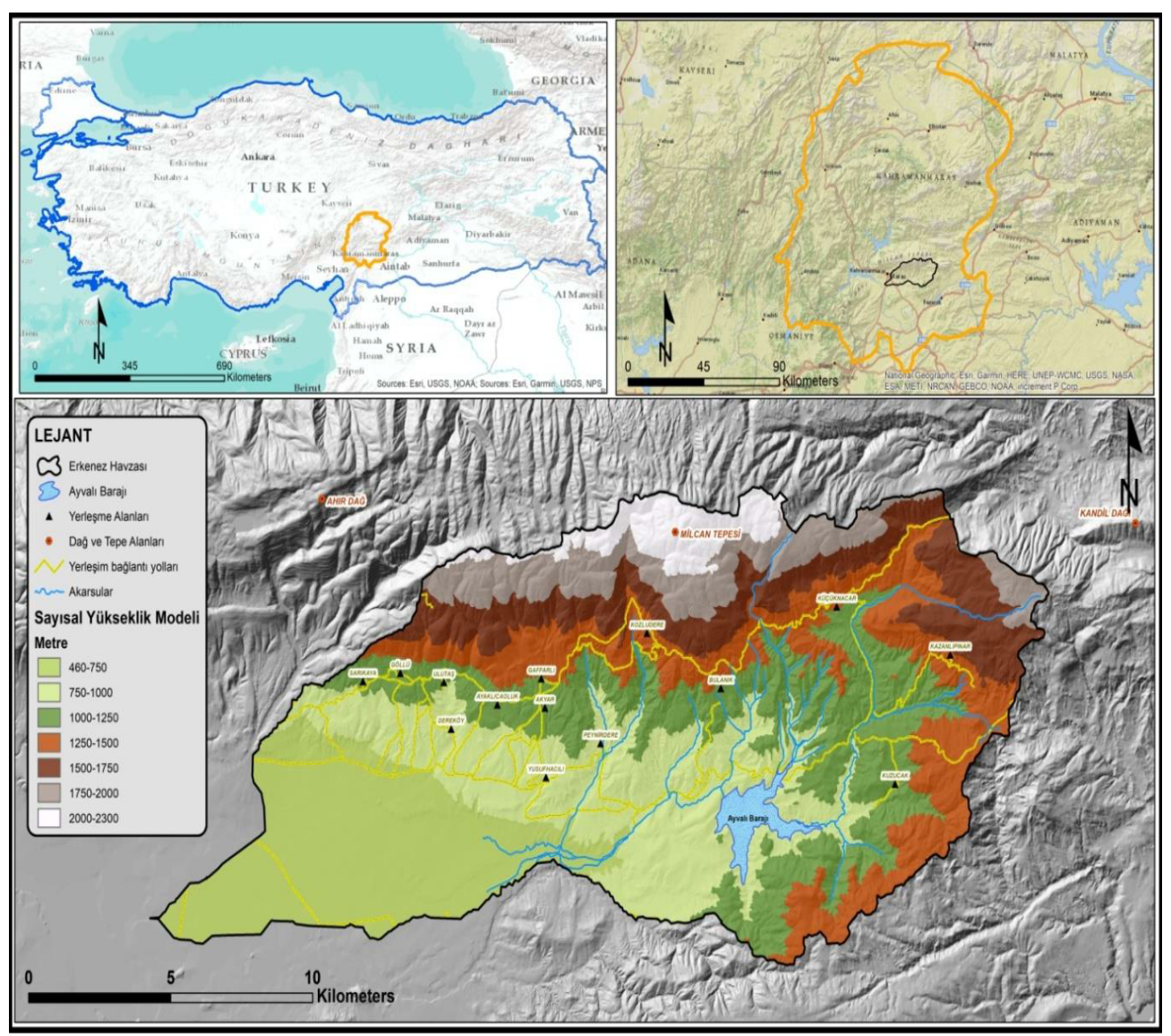

Sekil 1. Erkenez Havzası'nın konumu ve yükselti basamakları haritası

\section{MATERYAL VE YÖNTEM}

Arazide yer alan jeolojik birimlerinin türü, toprak veya kaya tipi, eğim açısı, arazi kullanımı ve örtüsü, yükseklik ve bakı duyarlılık parametreleri arasında yer almaktadır [26]. Bu çalışmada kullanılan CBS Matris modelinde uluslararası ve ulusal literatürde en sık kullanılan yedi faktör yapılan saha çalışmaları ve heyelanlı alan etkileri incelenerek seçilmiştir [17,27-29]. Bunlardan üç tanesi sayısal yükseklik modelinde türetilen eğim, eğim yüksekliği ve bakı, litoloji haritası ve arazi kullanımı verileri yer almaktadır. Model üzerinde değișiklik yapılarak, analizlerin daha da tutarlı ve uygun sonuçlar vermesi açısından Topoğrafik Nemlilik İndeksi (TWI) ve Normalize Fark Bitki İndeksi (NDVI) gibi heyelan duyarlılık çalışmalarında farklı parametreler eklenmiştir.

Heyelan duyarlılık çalışmaları heyelana etki eden faktörleri belirleyen ve bu faktörleri birlikte değerlendiren analitik bir süreçtir. Çalışma kapsamında Kahramanmaraş ili sınırları içerisinde yer alan Erkenez Havzasının heyelana duyarlı alanlar değerlendirilmiştir. Analiz CBS ortamında dikkate alınan faktör türleri arasındaki olası tüm kombinasyonların belirlenmesine dayanan matris yöntemi kullanılarak gerçekleştirilmiştir [30-33]. 
Heyelan envanteri kullanılarak her faktör kombinasyonundaki heyelanlardan etkilenen yüzey alanı hesaplanarak "Heyelan Matrisi" (Şekil 2a) oluşturulmaktadır. Bu aşamada faktör katmanları heyelanlı ve heyelansız olarak iki sınıfa ayrılmaktadır. Yönetim Birim Matrisinde, her faktör kombinasyonunun toplam yüzey alanı hesaplanmaktadır (Şekil 2b). Faktör sınıfları arasındaki tüm olası kombinasyonları gösteren bir harita üretmek üzere çakıştırma (overlay) yapılmaktadır. Çakıştırma katmanı kullanılarak çapraz tablo oluşturulup heyelanlı/heyelansız alanların dağılımı elde edilmektedir. Son olarak, Heyelan Duyarlılık Matrisinde (Şekil 2c), her bir piksel değeri, heyelan matrisine karşılık gelenler, yönetim birimi matrisindekilere bölünerek duyarlılık haritası üretilmektedir. Heyelan duyarlılık matrisi değerleri, heyelanların toplam alana oranını ve arazinin her noktasındaki her faktör kombinasyonunun göreceli duyarlılığını temsil etmektedir. Son olarak, elde edilen değerler, doğal-ayrım (natural-breaks) yöntemi kullanılarak 5 duyarlılık seviyesi (çok düşük, düşük, orta, yüksek, çok yüksek) ayrılmaktadır (Şekil 2d) $[27,31]$.

Duyarlılık analizleri sonucunda elde edilen değerlerin doğruluğu çalışma alanında gelişen güncel heyelanlar kullanılarak uyum derecesi (degree of fit: DF) yöntemi [27] ile gerçekleştirilmiştir. Bu yöntem ile Eşitlik 1 kullanılarak yeni gelişen heyelanlar ile oluşturulan kontrol heyelanlarının her bir duyarlılık seviyesi içindeki alansal dağılımları hesaplanmaktadır.

$\mathrm{DF}_{\mathrm{i}}=\left(\mathrm{m}_{\mathrm{i}} / \mathrm{t}_{\mathrm{i}}\right) / \sum\left(\mathrm{m}_{\mathrm{i}} / \mathrm{t}_{\mathrm{i}}\right)$

$\mathrm{m}_{\mathrm{i}}$; her bir duyarlılık seviyesinde (i) gerçekleşen heyelan alanı; $\mathrm{t}_{\mathrm{i}}$; kullanılan duyarlılık seviyesinin toplam alanıdır.

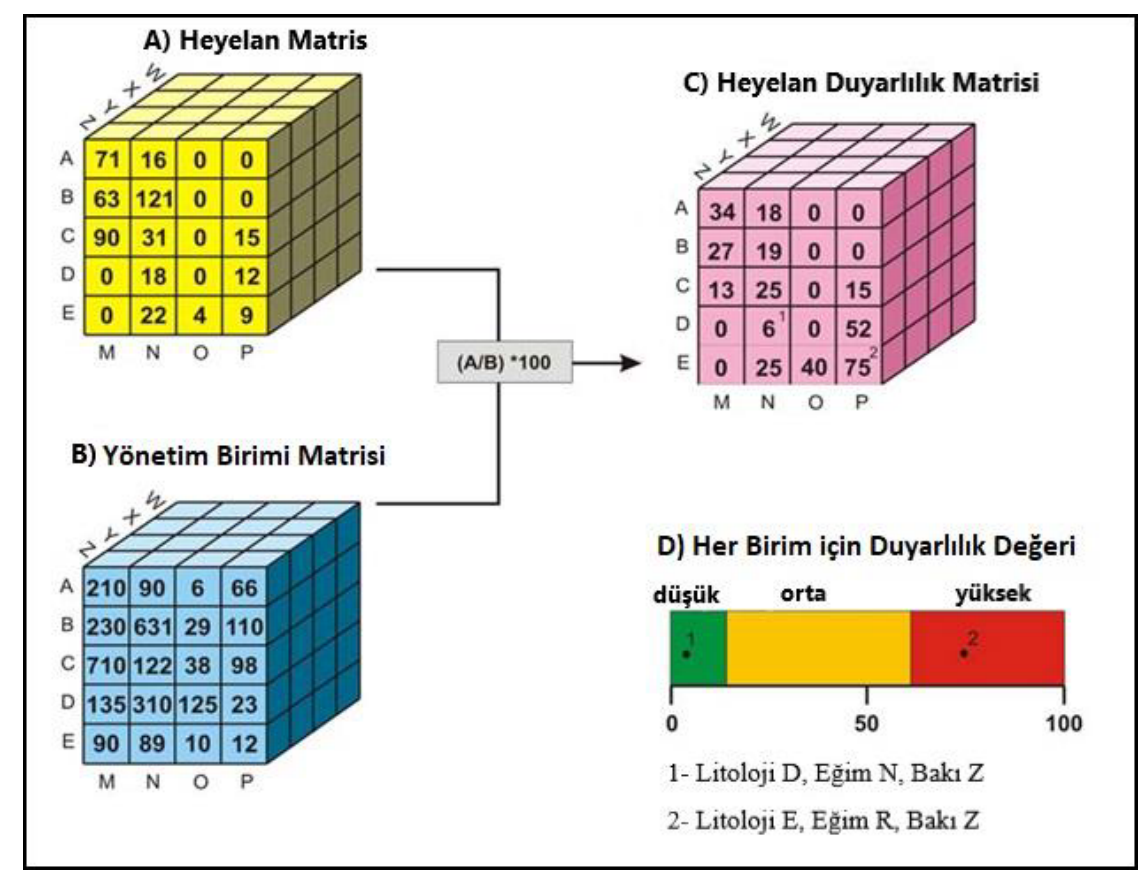

Şekil 2. CBS Matris Yaklaşımı için Duyarlılık Akış Şeması [27] A: Heyelan matrisi; B: Yönetim Birim Matrisi. C: Heyelan duyarlılık matrisi (A/B) *100; D: Her birimde duyarlılık sınıflarının düşük, orta, yüksek olarak faktörlerin ağırlıkları. A, B, C kullanılan faktörleri; Piksel değerleri: heyelan matrisinde, her kombinasyonun heyelanlı yüzey alanı, yönetim birim matrisinde, her kombinasyonun toplam yüzey alanı ve heyelan duyarlılık matrisinde, her kombinasyonun heyelanlı alan yüzdesidir 


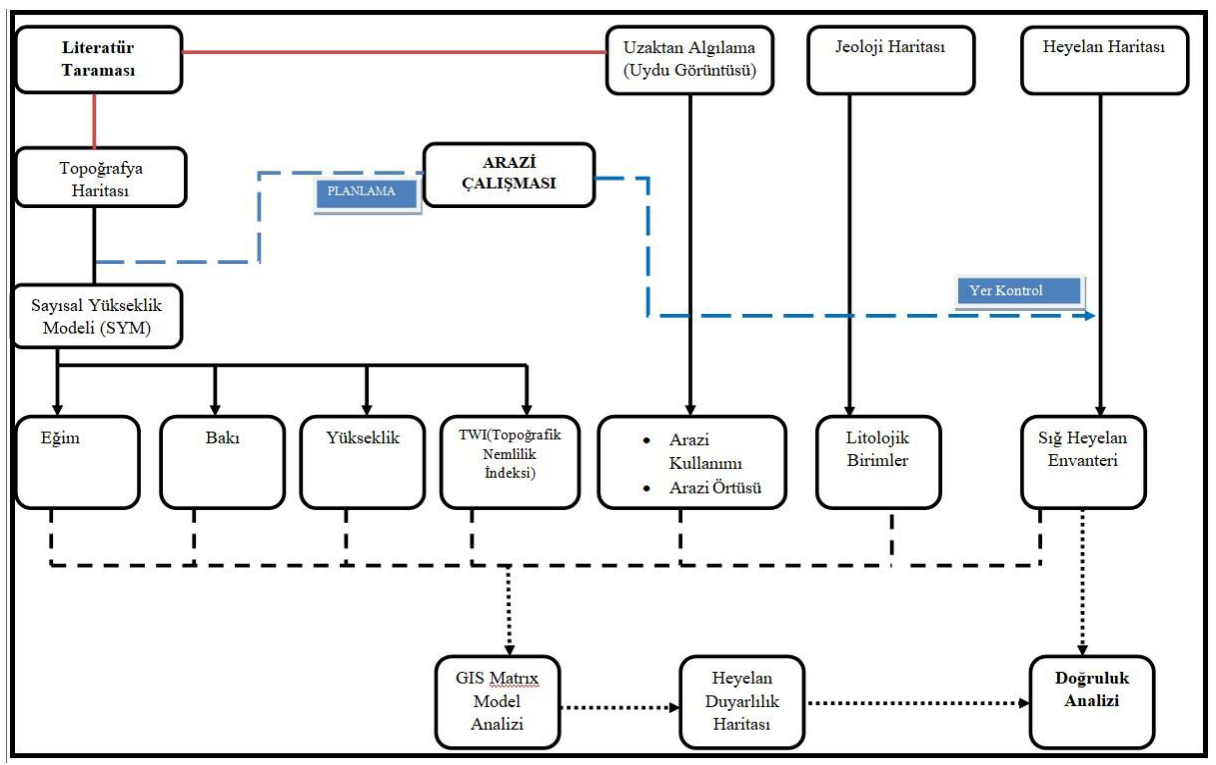

Şekil 3. Duyarlılık çalışmasında veri kullanımı ve iş akış şeması

Erkenez havzası heyelan duyarlılık çalışmasında izlenen çalışma adımları Şekil 3'te gösterilmiştir.

\section{BULGULAR VE TARTIŞMA}

\subsection{Heyelan Duyarlılı Analizlerinde Kullanılan Faktörler}

İstatistiksel bir olasılık yaklaşımı benimsediğinde, heyelan envanteri; duyarlılık, tehlike veya risk değerlendirmesi sağlamayı amaçlayan herhangi bir heyelan projesinde ilk adımdır [10]. Erkenez Havzası $265 \mathrm{~km}^{2}$ 'lik alana sahiptir. Tüm havza içerisinde heyelanlı alan dağılımı \%4,5' dir. Heyelan envanter verileri için Maden Tetik ve Arama Müdürlüğü'nün yaptığı 1/1.500.000 ölçekli Türkiye heyelan envanter haritası çalışması referans alınmıştır (Şekil 4) [34]. Ayrıca arazi çalışmaları ile havzadaki heyelan alanları tespit edilip haritalanarak envanter güncellenmiştir. Çalışma alanının heyelan envanteri incelendiğinde 93 tane heyelan alanı bulunmaktadır. Bu envanterde yer alan heyelan alanlarının 40 tanesi eski heyelan ve 53 heyelan alanı ise aktif heyelanlar sinıfındadır.

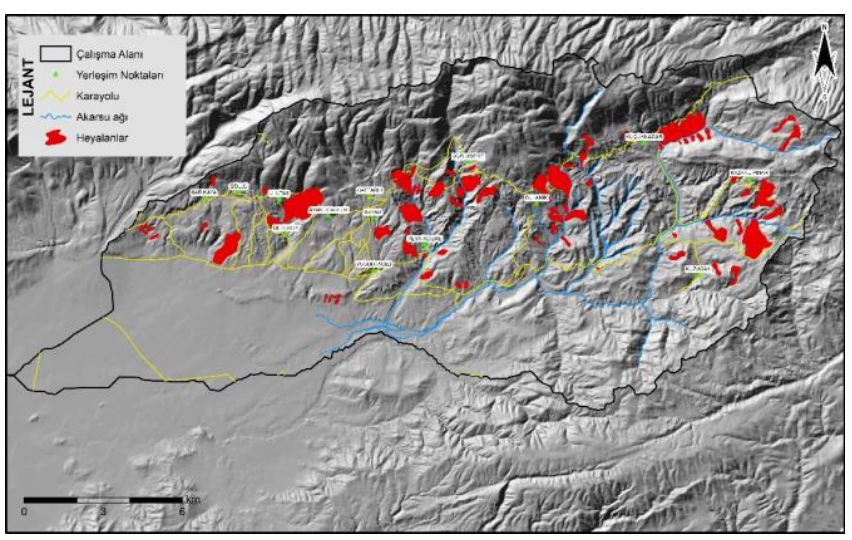

Şekil 4. Erkenez Havzası heyelan envanter haritası [34] 
Arabistan ve Anadolu levhalarının Kretase'den itibaren sıkışma rejiminin doğusunda yer alan Erkenez Havzasında birçok bindirme ve ters fayların gözlendiği aynı zamanda havzanın güneydoğusunda Pliyosen sonras1 deformasyon rejiminin bir sonucu olarak gelişen Doğu Anadolu Fay Zonu yer almaktadır [35,36]. Erkenez havzas1 genel stratigrafisi Jura-Kretase yerleşim yaşına sahip ofiyolitik kayaçlar üzerinde Eosen-güncel örtü kaya birimlerinden oluşmaktadır (Şekil 5) [37]. Çalışma alanı ile ilgili yapılan önceki çalışmalar incelendiğinde Jura-Kretase yaslı çoğunlukla serpantinit, peridotit, gabro, bazalt ve yabancı bloklardan oluşan oldukça karmaşık bir istif sunan ofiyolit ve ofiyolitik melanj bölgeye tektonik olarak yerleşmiş kayaçlar ile temsil edilmektedirler [38,39]. Bu birimler üzerinde Eosen-güncel yaslı şeyl, kiltaşı, marn, kumtaşı, çamurtası, çakılltası ve kireçtaşından oluşan örtü kaya birimleri ile Kuvaterner yaşlı alüvyonlar ve yamaç molozu bulunmaktadır [38,39].

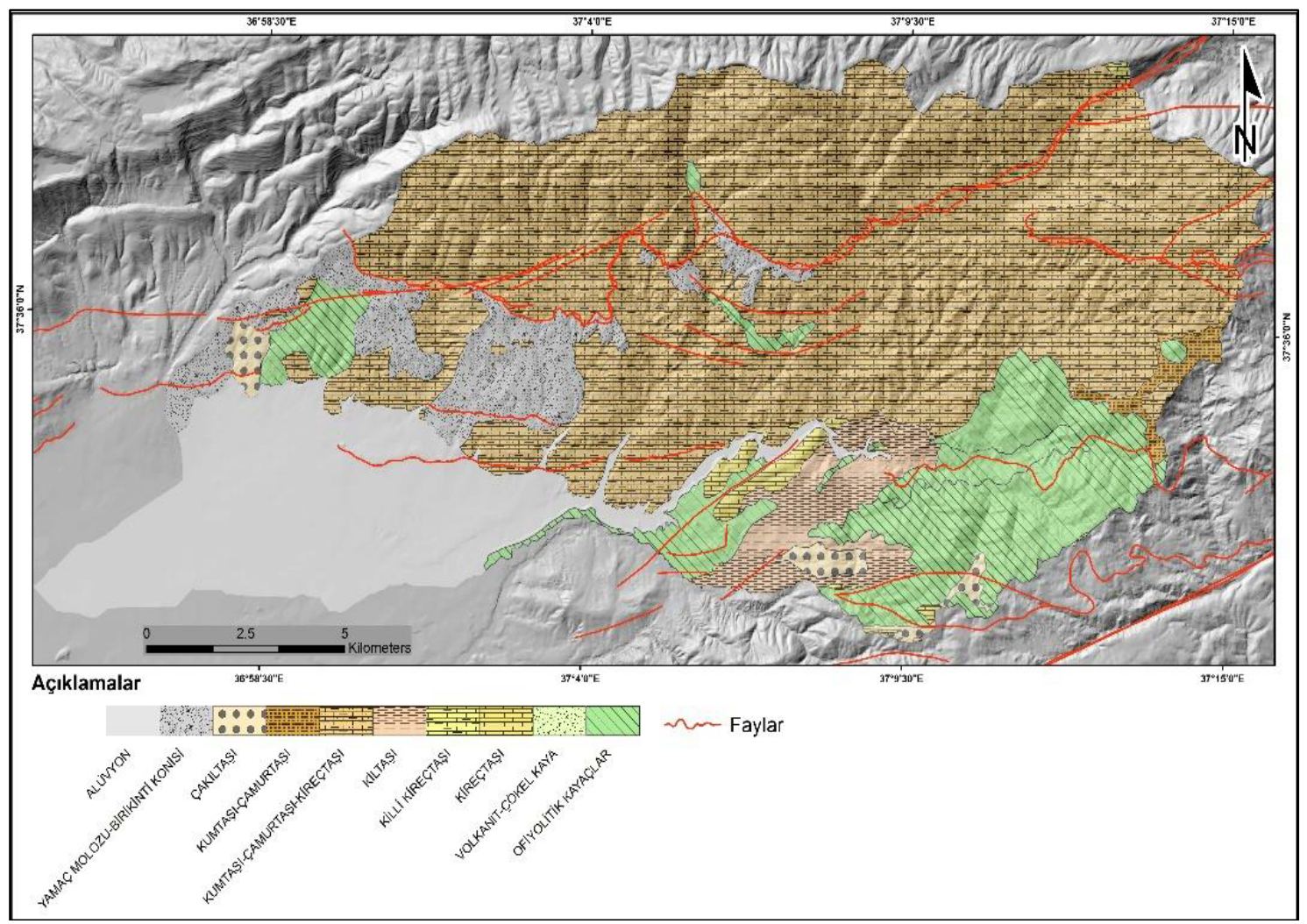

Şekil 5. Çalışma alanının genel jeoloji haritası [37]

Heyelan çalışmalarında eğim, arazinin topoğrafik yapısı ve morfolojik unsurlarının açıklanmasında önemli bir göstergedir [26]. Eğim; toprak yapısı, suya doygunluk, jeolojik faktörler gibi etkenlerle birlikte heyelana hazırlayıcı önemli bir faktördür. Çalışma sahası incelendiğinde heyelanların daha çok $10^{\circ}$ ile $25^{\circ}$ arası eğimli yamaçlarda meydana geldiği gözlenmektedir. Havzanın ova ve vadi taban bölümlerinde eğim 10o'nin altında heyelan gelişimi gözlenmeyen alanlardır (Şekil 6).

Bak1 faktörü, sahadaki nem, yağış, rüzgâr, güneşlenme süresi ve şiddeti gibi doğal ortam özellikleri üzerinde dolayısıyla ayrışma hızını kontrol etmektedir [40]. Bakı, heyelan üzerinde dolaylı bir etkiye sahiptir [26]. Çalışma alanında 
güney ve güney bileşenli bakıya sahip yamaçlarla heyelan aktiviteleri daha çok etkindir (Şekil 7).

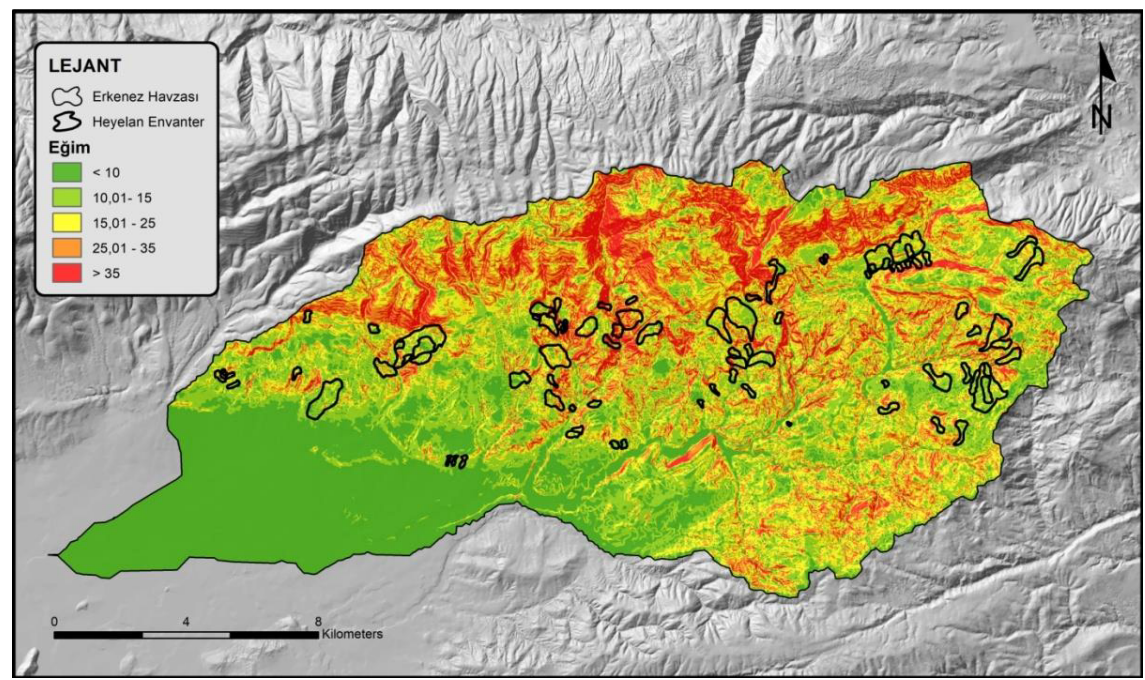

Şekil 6. Erkenez Havzası eğim haritası

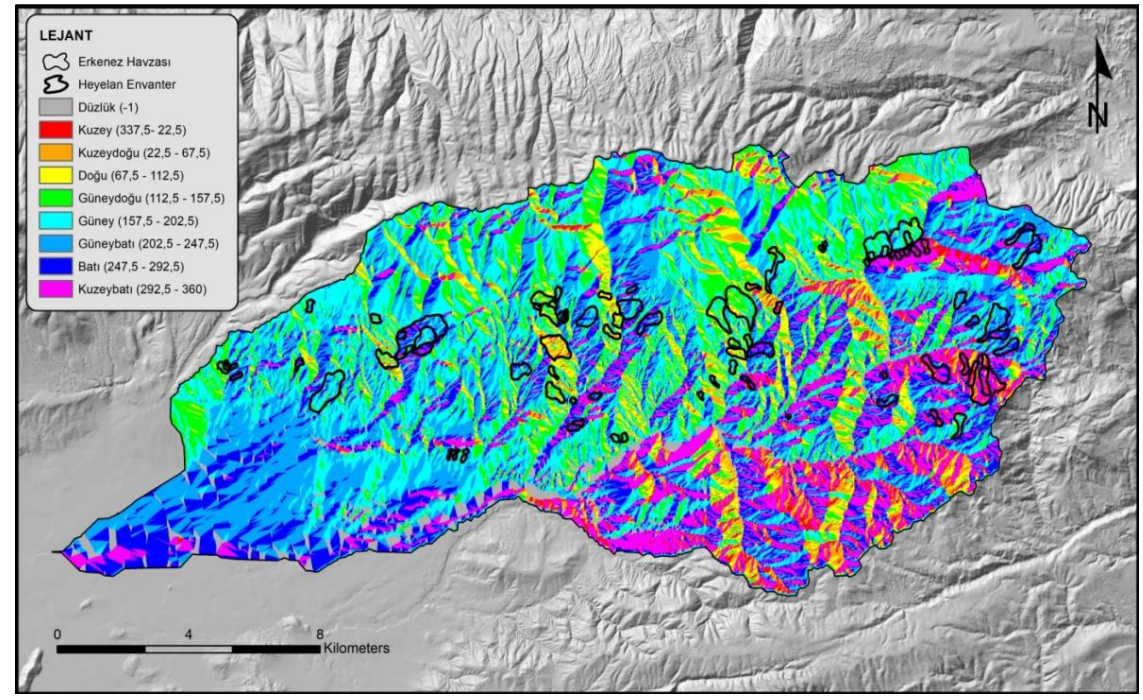

Şekil 7. Erkenez Havzası bakı haritası

Arazi kullanımı heyelan oluşumundan sorumlu anahtar faktörlerden bir diğeridir [41]. Buna karşılık, vejetatif alanlar yağmur gibi iklimsel etkenlerin etkisini azaltma eğilimindedir, böylece ağaç kökleri tarafından sağlanan doğal destek nedeniyle erozyonu önler ve bu nedenle yarı kurak bölgelerde ormanlık alanlar heyelanlara daha az eğilim gösterirler. Bu çalışmada arazi kullanım haritas1, Landsat 8 OLI/TIRS uydusu 11.08.2017 tarihli uydu görüntüsü üzerinden yapılan kontrolsüz sınıflama yöntemi ile oluşturulmuştur. Havzanın \%23'ünü oluşturan orman alanları çalışma alanının güneydoğu bölümlerinde yoğunlaşırken, kuzey kesimlerde seyrek bitki örtüsü ve kuru tarım faaliyetlerinin gerçekleştirildiği alanlar yer almaktadır (Şekil 8, Çizelge 1). 


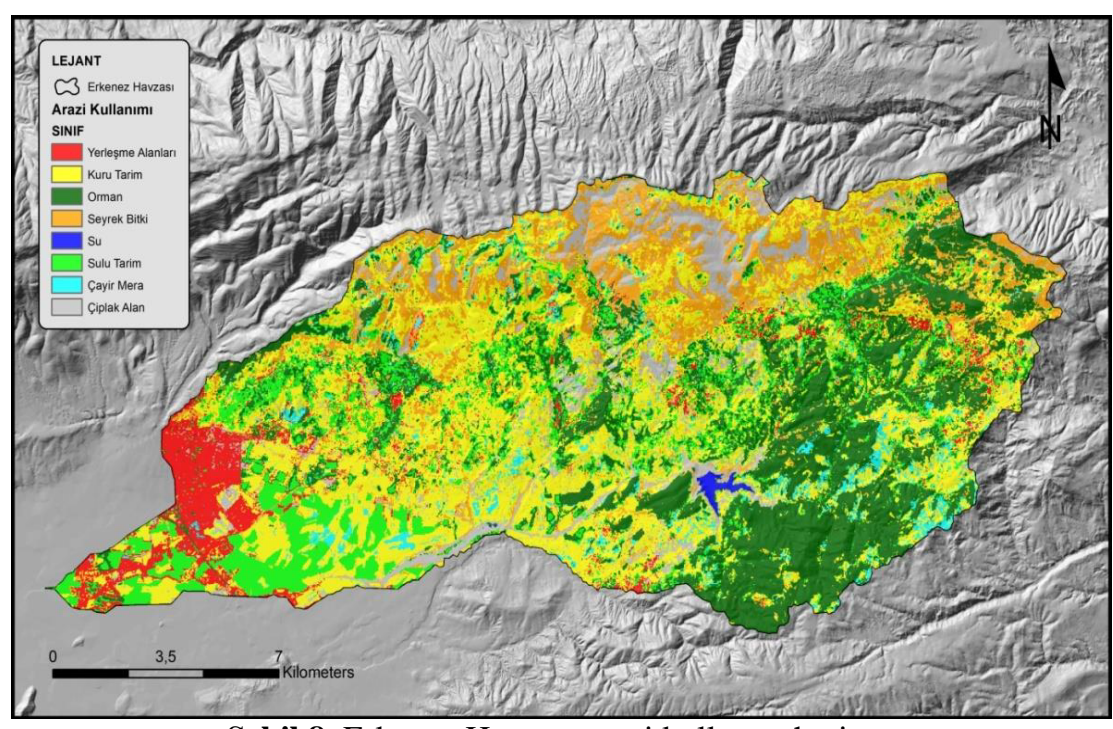

Şekil 8. Erkenez Havzası arazi kullanım haritası

Çizelge 1. Arazi kullanım sınıfları

\begin{tabular}{|c|c|c|c|c|c|c|c|c|}
\hline $\begin{array}{c}\text { Arazi Kullanım } \\
\text { Sinıfları }\end{array}$ & $\begin{array}{c}\text { Su } \\
\text { Yüzeyi }\end{array}$ & $\begin{array}{c}\text { Sulu } \\
\text { Tarım }\end{array}$ & $\begin{array}{c}\text { Kuru } \\
\text { Tarım }\end{array}$ & $\begin{array}{c}\text { Yerleşme } \\
\text { Alanları }\end{array}$ & $\begin{array}{c}\text { Orman } \\
\text { Alanları }\end{array}$ & $\begin{array}{c}\text { Çayır ve } \\
\text { Meralar }\end{array}$ & $\begin{array}{c}\text { Çılak (Kayalık) } \\
\text { Alanlar }\end{array}$ & $\begin{array}{c}\text { Seyrek Bitki } \\
\text { Alanları }\end{array}$ \\
\hline $\begin{array}{c}\text { Kapladığı Alan } \\
\left(\mathrm{km}^{2}\right)\end{array}$ & 0,6 & 34,5 & 89,6 & 15,8 & 62,3 & 10,4 & 19,8 & 32,4 \\
\hline
\end{tabular}

Heyelan duyarlılık değerlendirmelerinde arazi bitki yoğunluk durumunu belirten bir parametre olarak Normalize Fark Bitki İndeksi (NDVI) kullanılmaktadır. NDVI bitkilerin duyarlı olduğu uydu görüntülerinde yakın kızıl ötesi ve kırmızı spektral aralıkların oranlanması ile elde edilen bir indistir [29,42] (Eşitlik 2).

\section{NDVI=(Yakın Kızıl Ötesi-Kırmızı)/ (Yakın Kızıl Ötesi+Kırmızı)}

NDVI sonuç değerleri bitki örtüsünün yoğunluk durumuna göre -1 ve +1 değerleri arasında değişmektedir. NDVI değerleri 0,1 veya daha düşükse kayalık, çıplak alan gibi bitki örtüsünün bulunmadığı sahaları; 0,2 ile 0,3 arasında ise çayır, mera ya da yeşil çimenlik orta yoğunlukta bitki sahalarını; 0,6 ile 0,8 arasında ise bitki örtüsünün çok yoğun olduğu ormanlık sahaları ifade etmektedir [43]. Normalize fark bitki indeksi çalışma alanı için 11/08/2017 tarihli Landsat 8 OLI/TIRS uydu görüntüsü Kırmızı (band 4) ve
Yakın Kızılötesi (band 5) bandları formüle edilerek oluşturulmuştur (Şekil 9). Havzada vadi tabanları yüksek NDVI değerine sahipken havzanın kuzeyinde düşük NDVI değerleri görülmektedir.

Topoğrafik Nemlilik İndeksi (TWI) toprakların potansiyel doygunluk veya bir başka ifadeyle su tutma kapasitesinin belirlenmesine yönelik yapılan analizlerde kullanılan bir parametredir ve özellikle heyelana yönelik çalışmalarda çok sık kullanılmaktadır [29]. TWI değerleri yüzeysel akışın toplandığı vadi tabanlarında yüksek değerler sunmaktadır [14]. TWI akış yönünden türetilen, akış toplama alanı bilgisi ve eğim faktörlerinin bir bileşkesidir [44-46]. TWI formülü aşağıda yer almaktadır (Eşitlik 3);

$\mathrm{TWI}=\mathrm{In}(\mathrm{As} / \mathrm{Tan} \beta)$

As $=$ akış toplamı alanı- Tan $\beta=$ lokal eğim 


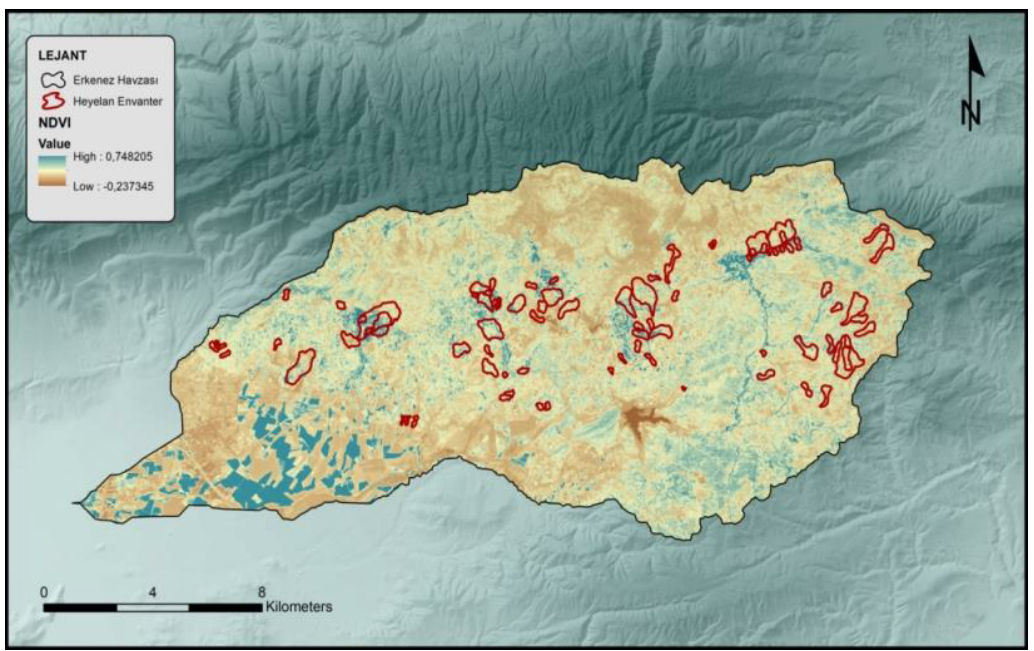

Şekil 9. Erkenez Havzası normalize fark bitki indeksi (NDVI) haritası

Burada TWI Topoğrafik Nemlilik İndeksini, As doğal logaritmik tabanda spesifik havza alanının $\left(\mathrm{m} / \mathrm{m}^{2}\right)$, yamaç eğimine oranını ifade etmektedir. Topoğrafik nemlilik endeks değerlerinin düşük olduğu yerler çalışma alanındaki sırtları; yüksek değerler ise alüvyal düzlükleri göstermektedir (Şekil 10).

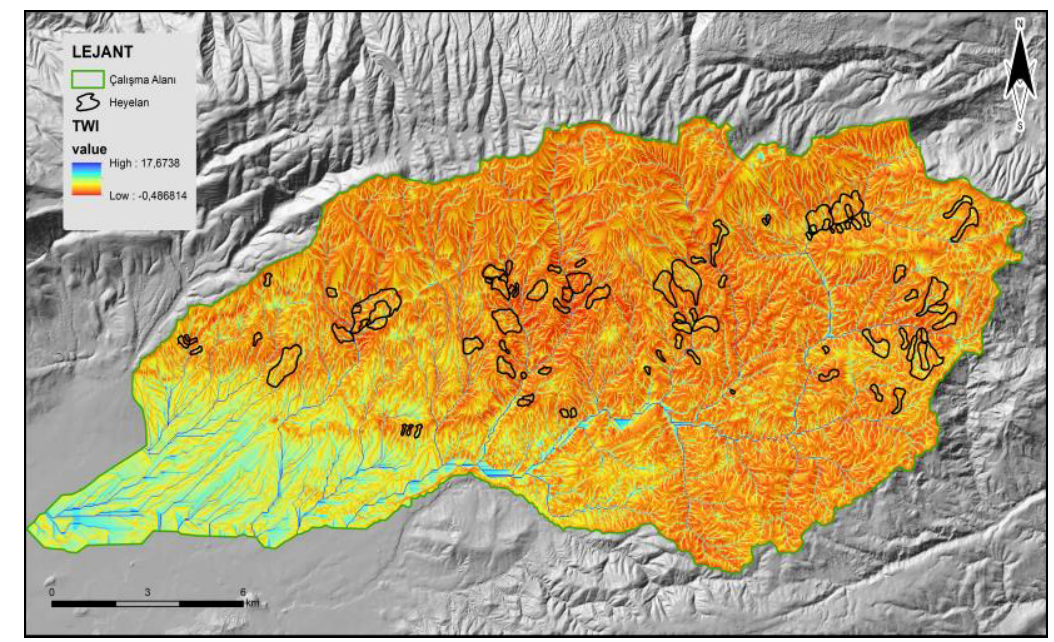

Şekil 10. Erkenez Havzası topoğrafik nemlilik indeks (TWI) haritası

\subsection{Heyelan Duyarlılı Analizi}

Erkenez havzası heyelan envanter haritasında, heyelanlar çalışma alanının \%4,5'ine karşılık gelmektedir. $\mathrm{Bu}$ çalışmada CBS Matris modelinde uluslararası ve ulusal literatürde en sık kullanılan yedi faktör eğim, yükseklik, bakı, litoloji haritası, arazi kullanımı, Topoğrafik Nemlilik İndeksi
(TWI) ve Normalize Fark Bitki İndeksi (NDVI) kullanılarak duyarlılık haritası oluşturulmuştur. Faktör katmanları yeniden sinıflandırıldıktan (Çizelge 2) ve vektörel bir formatta oluşturulduktan sonra, bu faktörlerin sınıfları arasındaki tüm kombinasyonlar ArcGIS programı geoprocessing araçları ile çakıştırılmıştır. 
Çizelge 2. Çalışma Alanına ait faktörlerin sınıflandırılması

\begin{tabular}{|l|l|l|}
\hline Ana Faktörler & Alt Faktörler & Altsınıflar \\
\hline \multirow{2}{*}{ Jeolojik } & Litoloji & $\begin{array}{l}\text { JKk, Tmy, Qal, Tmt, Qym, KTsq, Kbe, Tma, } \\
\text { Tkd, PlQb, Kbes, Qav }\end{array}$ \\
\hline \multirow{3}{*}{ Jeomorfoloji } & Yükselti $(\mathrm{m})$ & $\begin{array}{l}460-750,750-1000,1000-1250,1250-1500, \\
1500-1750,1750-2000,2000-2338\end{array}$ \\
\cline { 2 - 3 } & Eğim $\left(^{\circ}\right)$ & $<10,10,1-15,15,01-25,25,01-35,>35$ \\
\cline { 2 - 3 } & Bakı & $\begin{array}{l}\text { Sekiz ana yön }(\mathrm{K}, \mathrm{KD}, \mathrm{D}, \mathrm{GD}, \mathrm{G}, \mathrm{GB}, \mathrm{B}, \mathrm{KB}) \\
\text { ve düz alanlar }\left(-1^{\circ}\right)\end{array}$ \\
\hline \multirow{2}{*}{ Hidroloji } & TWI (Topoğrafik nemlilik indeksi) & $\begin{array}{l}(-0-1,7,1,7-2,7,2,7-3,8,3,8-5,1,5,1-6,4,6,4- \\
8,02,8,02-10,08,10,08-12,9)\end{array}$ \\
\hline & & Sulak, Sulu ve Kuru Tarım, Kentsel \\
\hline & & Ormanlık, Seyrek Bitki Örtüsü, Çayır ve Mera \\
\hline Arazi Kullanım & Arazi örtüsü ve kullanımı & Kavalık-Çıplak Alanlar \\
\hline & NDVI (Normalize fark bitki indeksi) & $(-0,23,-0,24,-0,24-0,42,0,42-0,74)$ \\
\hline
\end{tabular}

CBS Matris modeli ile üretilen heyelan duyarlılık haritalarına göre havza içerisinde \%6,97'si düşük, $\% 3,11$ 'i orta, \%1,37'si yüksek, \%1,2'si çok yüksek derecede heyelana duyarlı alanlar olarak tespit edilmiştir (Şekil 11).

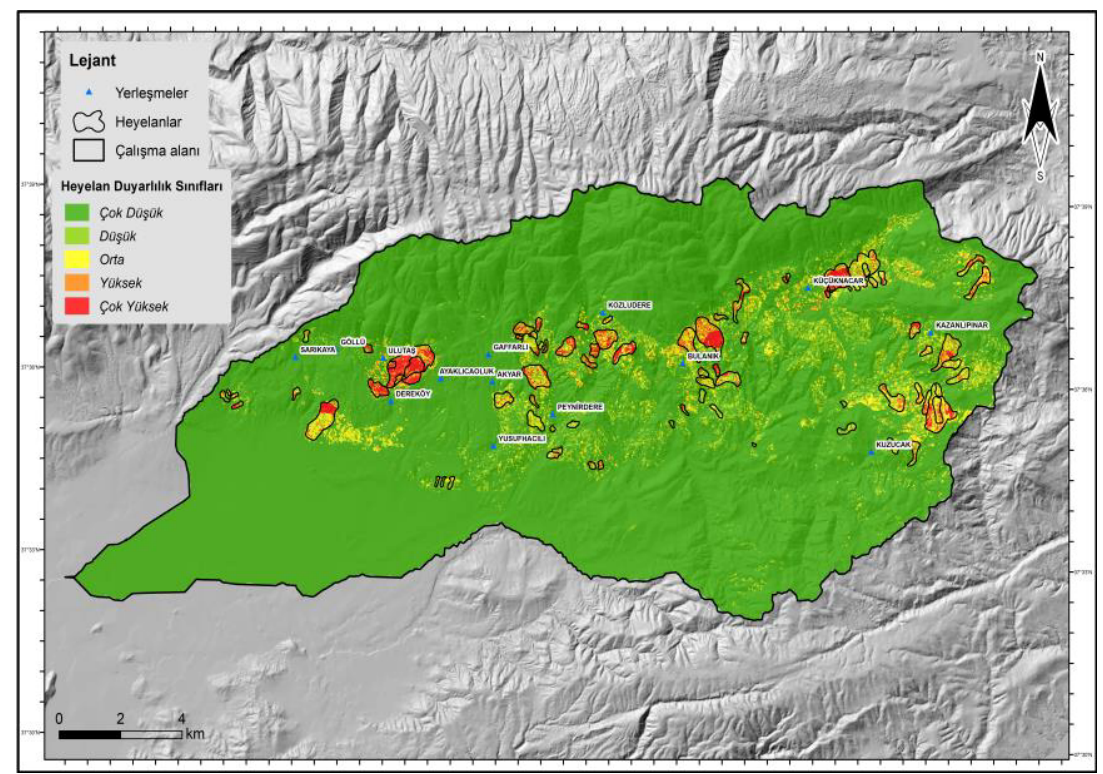

Şekil 11. Erkenez Havzası heyelan duyarlılık haritası

Duyarlılık sonuçlarına göre 14/01/2019 tarihinde Dereköy, 21/04/2019 tarihinde Kuzucak ve 10/05/2020 tarihinde Peynirdere 'de yapılan saha çalışmalarında özellikle eski heyelan kütleleri içerisinde yeni akma ve rotasyonel heyelan gelişimleri gözlenmiştir (Şekil 12).
Duyarlılık haritalarının doğruluk analiz sonuçlarına göre çok düşük ve düşük duyarlılık seviyelerinin uyum derecesi 7,32 iken çok yüksek duyarlı olarak tespit edilen alanların uyum derecesi 45,33 olarak hesaplanmıştır (Şekil 13). 


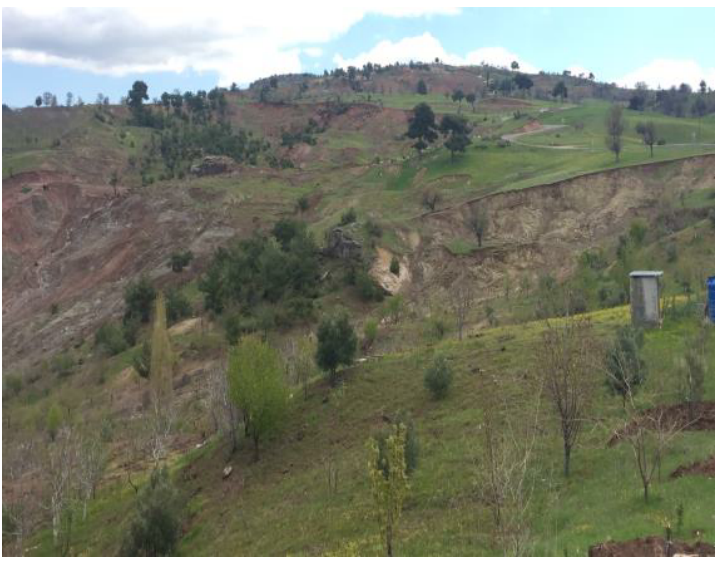

(a)

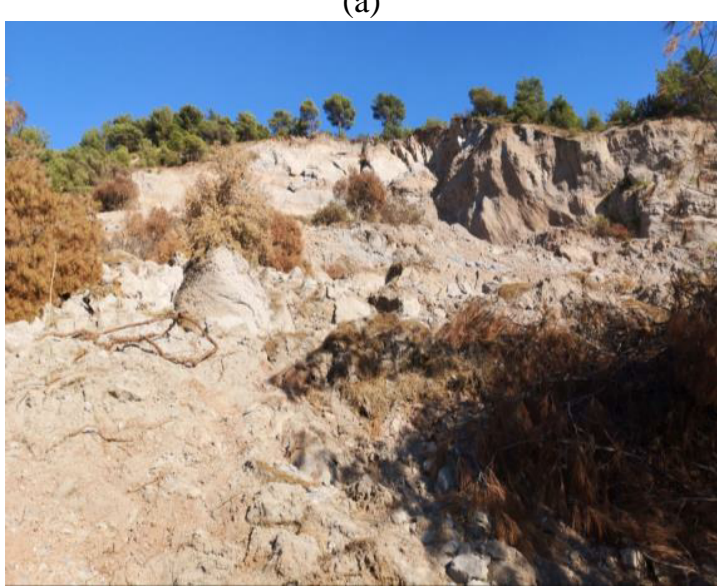

(b)

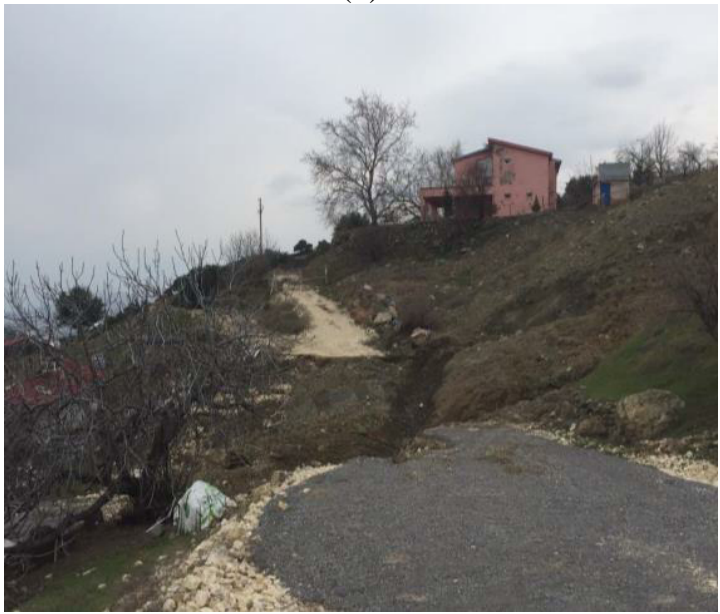

(c)

Şekil 12. Erkenez Havzası'nda a) Kuzucak, b) Peynirdere, c) Dereköy, yerleşimlerinde heyelanlı sahalar

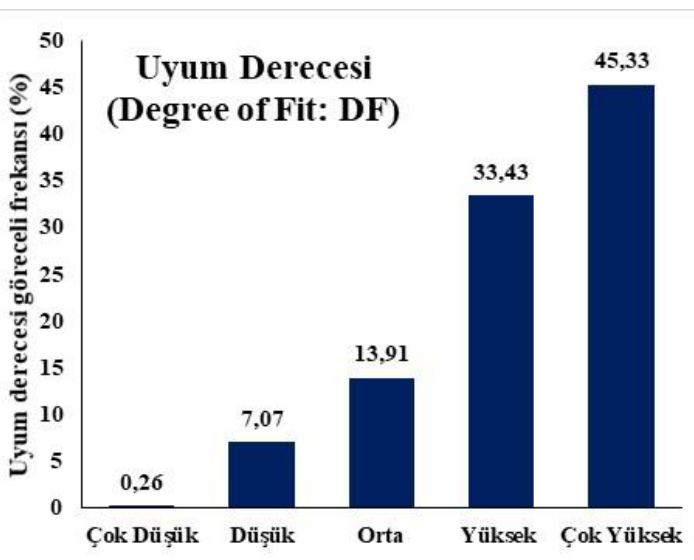

Şekil 13. Uyum derecesi (DF) sonuçlarının duyarlılık seviyeleri dağılımı

\section{SONUÇLAR}

Heyelanların dağılımını belirleyen ve oluşumunu sağlayan çok sayıda faktör vardır. Jeolojik, jeomorfolojik ve klimatik faktörler en önemlileridir. Heyelan duyarlılık haritaları, heyelan kaynaklı riskleri en aza indirmeyi amaçlayan karar-destek araçlarıdır. Bu çalışmada CBS Matris modeli ile bölgesel ölçekte heyelan duyarlılık haritalaması ve doğrulama için otomatik bir süreç oluşturulmaya çalışılmıştır.

Bu çalışmada, Kahramanmaraş ili Erkenez Havzasında heyelan duyarlılık analizleri yapılmıştır. Çalışma için bütün heyelan türleri için heyelana neden olan faktörler belirlendikten sonra heyelan duyarlılık haritaları oluşturulmuştur. Havza içerisinde \%6,97'si düşük, \%3,11'i orta, $\% 1,37$ 'si yüksek, \%1,2'si çok yüksek derecede heyelana duyarlı alanlar olarak tespit edilmiştir. Duyarlı alanların önemli bir bölümü tarımsal nitelikteki arazi kullanım alanlarında yoğunlaşmaktadır. Diğer duyarlı alanlar litoloji ile ilişkili olarak killi ve gevşek karasal kırıntılı birimler içerisinde gözlenmektedir. Yeni gelişen heyelanlar ile yapılan doğruluk analizleri yaklaşık \%79 doğruluk ile heyelana duyarlı alanların örtüştüğünü göstermektedir. Bağıl hata oran1 yaklaşık \%7 olması çalışma alanında küçük akmaların kullanılan sayısal yükseklik modeli çözünürlüğü ve daha detaylı litoloji haritalamasına ihtiyaç olması ile ilişkili olarak 
yakalanamamasından düşünülmektedir.

kaynaklandığ

CBS temelli bu yaklaşımla elde edilen sonuçlar ilerleyen süreçlerde heyelan olası risk haritalama çalışmalarına bir altlık oluşturulacaktır. Duyarlılık haritaları aynı zamanda mekânsal planlama ve heyelanlar ile ilişkili afet yönetimi aşaması karar alım süreçlerinde ana sınırlılıkların belirlenmesi ve ayrıca uygun önleyici ve iyileştirici önlemlerin alınması gereken alanların tespiti gibi uygulama aşamalarında dikkate alınması olumlu sonuçlar ortaya çıkaracaktır.

\section{TEŞEKKÜR}

Yayının değerlendirme sürecinde yer alan hakemlere katkı ve önerilerinden dolayı teşekkür ederiz.

\section{KAYNAKLAR}

1. Dragovich, J.D., Brunengo, M.J., 1995. Landslide Map and Inventory, Tilton RiverMineral Creek Area, Lewis County, Washington. Wash. Dept. Natural Resources, Div. of Geology and Earth Resources, OpenFile Report, 95-1, 165.

2. Guzzetti, F., Carrara, A., Cardinali, M., Reichenbach, P., 1999. Heyelan Tehlike Değerlendirmesi: Mevcut Tekniklerin Gözden Geçirilmesi ve Çok Ölçekli Bir Çalışmadaorta İtalya, Jeomorfoloji, 31(1-4), 181-216.

3. Dağ, S., Bulut, F., 2012. Coğrafi Bilgi Sistemleri Tabanlı Heyelan Duyarlılık Haritalarının Hazırlanmasına Bir Örnek: Çayeli (Rize, KD Türkiye). Jeoloji Mühendisliği Dergisi, 36(1), 35-62.

4. Kavzoğlu, T., Şahin, E.K., Çölkesen, İ., 2012. Heyelan Duyarlılığının İncelenmesinde Regresyon Ağaçlarının Kullanımı: Trabzon Örneği. Harita Dergisi, 147(3), 21-33.

5. Chen, W., Li, Y., 2020. GIS-Based Evaluation Of Landslide Susceptibility Using Hybrid Computational Intelligence Models. Catena, 195, 104777.

6. Guzzetti, F., Mondini, A.C., Cardinali, M., Fiorucci, F., Santangelo, M., Chang, K.T.,
2012. Landslide Inventory Maps: New Tools for an Old Problem. Earth-Sciencereviews, 112(1-2), 42-66.

7. Radbruch, D.H., Crowther, K.C., 1970. Map Showing Relative Amounts of Landslides in California (No. 70-270). https://doi.org/ 10.3133/ofr70270

8. Dobrovolny, E., 1971. Landslide Susceptibility in and Near Anchorage as Interpreted from Topographic and Geologic Maps, in the Great Alaska Earthquake of 1964-Geology Volume. Publication 1603. US Geological Survey Open File Report, 86-329.

9. Brabb, E.E., Pampeyan, E.H., Bonilla, M.G., 1972. Landslide Susceptibility in San Mateo County, California (No. 360). US Geological Survey, 1.

10. Chacón, J., Irigaray, C., Fernandez, T., El Hamdouni, R., 2006. Engineering Geology Maps: Landslides and Geographical Information Systems. Bulletin of Engineering Geology and the Environment, 65(4), 341-411.

11. Evans, N.C., King, J.P., 1998. The Natural Terrain Landslide Study: Debris Avalanche Susceptibility. Technical Note TN 1/98. Planning Division. Geotechnical Engineering Office, Civil Engineering Department, Hong Kong, 96.

12. Evans, N.C., Huang, S.W., King, J.P., 1997. The Natural Terrain Landslide Study-Phases I and II. Special Project Report SPR5/97. Geotechnical Engineering Office, Hong Kong, 420.

13. Chacón, J., Corominas, J., 2003. Special Issue on Landslides and GIS. Natural Hazards, 30, 263-499.

14. Tekin, S., Çan, T., 2019. Yapay Sinir Ağları Yöntemi ile Ermenek Havzası'nın (Karaman) Kayma Türü Heyelan Duyarlılık Değerlendirmesi. Bilge International Journal of Science and Technology Research, 3(1), 21-28.

15. Clerici, A., Perego, S., Tellini, C., Vescovi, P., 2002. A Procedure for Landslide Susceptibility Zonation by the Conditional Analysis Method. Geomorphology, 48(4), 349-364.

16. Lee, S., Ryu, J.H., Min, K., Won, J.S., 2003. Landslide Susceptibility Analysis Using GIS and Artificial Neural Network. Earth Surface Processes and Landforms: The Journal of the 
British Geomorphological Research Group, 28(12), 1361-1376.

17. Fernández, T., Irigaray, C., El Hamdouni, R., Chacón, J., 2003. Methodology for Landslide Susceptibility Mapping By Means of a GIS. Application to the Contraviesa Area (Granada, Spain). Natural Hazards, 30(3), 297-308.

18. Süzen, M.L., Doyuran, V., 2004. Data Driven Bivariate Landslide Susceptibility Assessment Using Geographical Information Systems: A Method and Application to Asarsuyu Catchment, Turkey. Engineering Geology, 71(3-4), 303-321.

19. Ercanoglu, M., Gokceoglu, C., 2004. Use of Fuzzy Relations to Produce Landslide Susceptibility Map of a Landslide Prone Area (West Black Sea Region, Turkey). Engineering Geology, 75(3-4), 229-250.

20. Ayalew, L., Yamagishi, H., 2005. The Application of GIS-Based Logistic Regression for Landslide Susceptibility Mapping in the Kakuda-Yahiko Mountains, Central Japan. Geomorphology, 65(1-2), 15-31.

21. Lee, S., Talib, J.A., 2005. Probabilistic Landslide Susceptibility and Factor Effect Analysis. Environmental Geology, 47(7), 982-990.

22. Reis, S., Yalçın, A., Atasoy, M., Nişancı, R., Bayrak, T., Sancar, C., Ekercin, S., 2009. CBS ve Uzaktan Algilama Teknikleri ile Heyelan Duyarlılık Haritalarının Üretimi: Rize İli Örneği. Türkiye Ulusal Fotogrametrive Uzaktan Algılama Birliği V. Teknik Sempozyumu (TUFUAB 2009), Ankara

23. Tekin, S., Çan, T., 2019. Ermenek Havzasının Yapay Sinir Ağları Yöntemi İle Heyelan Duyarlılık Değerlendirmesi, 1, 21-28. doi: 10.30516/bilgesci.525438.

24. Pham, B.T., Tien Bui, D., Indra, P., Dholakia, M., 2015. Hindistan, Uttarakhand Himalaya'nın Bir Bölümünde, Frekans Oranı Yönteminin CBS Tabanlı İstatistiksel Yaklaşımı Kullanılarak Heyelan Duyarlılık Değerlendirmesi. Int J Eng Res Technol, 4(11), 338-344.

25. Dağdelenler, G., 2020. İki Farklı Örneklem Tekniği Kullanılarak Oluşturulan Heyelan Duyarlılık Haritalarının Frekans Oranı (FO)
Yöntemi ile Karşılaştırılması. Jeoloji Mühendisliği Dergisi, 44(1), 19-38.

26. Fernández, T., Jiménez, J., Fernández, P., El Hamdouni, R., Cardenal, F.J., Delgado, J., Chacón, J., 2008. Automatic Detection of Landslide Features with Remote Sensing Techniques in the Betic Cordilleras (Granada, Southern Spain). Int Soc Photogramme, 37(8), 351-356.

27. Irigaray, C., Fernández, T., El Hamdouni, R., Chacón, J., 2007. Evaluation Andvalidation of Landslide-Susceptibility Maps Obtained by a GIS Matrix Method: Examples from the Betic Cordillera (Southern Spain). Natural Hazards, 41(1), 61-79.

28. Ayalew, L., Yamagishi, H., 2005. The Application of GIS-Based Logistic Regression for Landslide Susceptibility Mapping in the Kakuda-Yahiko Mountains, Central Japan. Geomorphology, 65(1-2), 15-31.

29. Erener, A., Sarp, G., Duzgun, S.H., 2019. Use of GIS and Remote Sensing for Landslide Susceptibility Mapping. In Advanced Methodologies and Technologies in Engineering and Environmental Science, IGI Global, 384-398pp.

30. Degraff, J.V., Romesburg, C., 1980. Regional Landslide Susceptibility Assessment for Wildland Management: A Matrix Approach.

31. Irigaray, C., 1995. Movimientos De Ladera: Inventario, Análisis Y Cartografía de Susceptibilidad Mediante un Sistema de Información Geográfica (SIG). Aplicación a Las Zonas de Colmenar (Ma), Rute (Co) Y Montefrío (Gr) (Doctoral Dissertation, Universidad de Granada).

32. Fernández, C.I., Del Castillo, T.F., Hamdouni, R.E., Montero, J.C., 1999. Verification of Landslide Susceptibility Mapping: A Case Study. Earth Surface Processes and Landforms: The Journal of the British Geomorphological Research Group, 24(6), 537-544.

33. Chacón, J., Irigaray, C., Fernandez, T., El Hamdouni, R., 2006. Engineering Geology Maps: Landslides and Geographical Information Systems. Bulletin of Engineering Geology and the Environment, 65(4), 341-411.

34. Duman, T.Y., Çan, T., Olgun, Ş., Nefeslioğlu, H.A., Durmaz, S., Hamzaçebi, S., Elmacı, H., 
Çörekçioğlu, Ş., 2009. Türkiye Heyelan Envanteri Haritas1-1:500.000 Ölçekli Hatay Paftası, MTA Özel Yayınlar Serisi 24, Ankara, 23.

35. Varol, L., Alican, K.O.P., Darbaş, G., 2012. Koçlar-Sarıüzel (Kahramanmaraş Kuzeyi) Arasında Kalan Bölgenin Genel Jeolojik Özellikleri, Doğu Toroslar. Kahramanmaraş Sütçü İmam Üniversitesi Mühendislik Bilimleri Dergisi, 15(1), 43-56.

36. Duman, TY, Emre, Ö., 2013. The East Anatolian Fault: Geometry, Segmentation and Jog Characteristics, In: Robertson, A.H.F., Parlak, O., and Ünlügenç, U.C., (Eds.), Geological Development of Anatolia and Easternmost Mediterranean Region. Geological Society, London, Special Publication. 372, 495-529.

37. Ulu, Ü., 2002. 1:500.000 Ölçekli Türkiye Jeoloji Haritası Hatay Paftası. Türkiye 1/500.000 Ölçekli Jeoloji Haritaları, No: 16, M. Şenel (Ed.), Maden Tetkik ve Arama Genel Müdürlüğü, Ankara.

38. Erkmen, C., Eravc1, B., Özsaraç, V., Yaman, M., Tekin, B.M., Albayrak, H., Kuterdem, K., Aktan, T., Tepeuğur, E., 2009. Doğu Anadolu Fayı'nın Paleosismolojisi Pilot Bölge: “Türkoğlu Gölbası Arası”. Türkiye Ulusal Jeodezi ve Jeofizik Birliği (TUJJB) Ulusal Deprem Programı Proje No: TUJJB-UDP-1-07.

39. Yalçın, C., 2012. Çağlayancerit (Kahramanmaraş) Batısının TektonoStratigrafisi ve Yapısal Evrimi. Kahramanmaraş Sütçü İmam Üniversitesi Fen Bilimleri Enstitüsü, Yüksek Lisans Tezi, 129.

40. Akar, İ., 2007. Jeomorfoloji Analizlerinde Coğrafi Bilgi Sistemleri Tekniklerinin Kullanımı: Kasatura Körfezi Hidrolojik Havzası Örneği. Türkiye Kuaterner Sempozyumu, İstanbul Teknik Üniversitesi, Avrasya Enstitüsü, İstanbul.

41. Dahal, R.K., Hasegawa, S., Nonomura, A., Yamanaka, M., Masuda, T., Nishino, K., 2008. GIS-based Weights-of-evidence Modelling of Rainfall-induced Landslides in Small Catchments for Landslide Susceptibility Mapping. Environmental Geology, 54(2), 311-324.
42. Karabulut, M., 2015. Farklı Uzaktan Algılama Teknikleri Kullanılarak Göksu Deltası Göllerinde Zamansal Değişimlerin Incelenmesi. Journal of International Social Research, 8(37), 347-347.

43. Çelik, M., Karabulut, M., 2013. Yağış Koşullarının Antep Fıstığı (Pistacia Vera L.) Biomas Aktivitesi ve Fenolojik Özelliklerine Etkisinin Uzaktan Algilama Verileri Kullanılarak incelenmesi. Türk Coğrafya Dergisi, (60), 37-48.

44. Quinn, P.F., Beven, K.J., Lamb, R., 1995. The Ln $(A / \operatorname{Tan} \beta)$ Index: How to Calculate it and How to Use it Within the Topmodel Framework, Hydrological Processes 9, 161-182.

45. Sorenson, R., Zinko, U., Seibert, J., 2005. On the Calculation of the Topographic Wetness Index: Evaluation of Different Methods Based on Field Observations, Hydrology and Earth Systems Sciences Discussions, 2, 1807-1834.

46. Gomez, H., Kavzoglu, T., 2005. Assessment of Shallow Landslide Susceptibility Using Artificial Neural Networks in Jabonosa River Basin, Venezuela. Engineering Geology, 78 (1-2), 11-27.

47. MGM, İllere Ait Mevsim Normalleri (19812010) https://www.mgm.gov.tr/veri degerlendirme/il-ve-ilceler-istatistik.aspx $? \mathrm{k}=\mathrm{u}$ ndefined\&m=K.MARAS, 10.09.2020. 